\title{
Corporalidad ciudadana y subjetivación escolar en México (1940-1950): la biotipología de José Gómez Robleda
}

\section{Citizens' Corporality and Scholar Subjectivation in Mexico (1940-1950): the Biotypology of José Gómez Robleda}

\author{
Gustavo Adolfo Enríquez Gutiérrez* \\ Uziel Mauricio Morales Hernández ${ }^{* *}$
}

* Profesor de la Universidad Pedagógica Nacional, Unidad 171, Morelos (México). Doctor en Educación por el Instituto de Ciencias de la Educación (ICE) de la UAEM. Entre sus publicaciones recientes están: "Contornos y límites corporales del hombre medio en México (1930-1960) en Revista Corpo-grafias: Estudios críticos y desde los cuerpos (2020) y "La formación de capacidades en la modernidad a través de la familia y la escuela" en Revista Latinoamericana de Estudios sobre Cuerpos, Emociones y Sociedad (2019). Cuenta con reconocimiento al Perfil Prodep y del Sistema Nacional de Investigadores, nivel candidato.Correo electrónico: gusen68@hotmail.com

(D) https://orcid.org/0000-0002-2099-9072

** Profesor-investigador de la Red de Docentes Transdisciplinar de México S.C. (México). Es maestro en Educación Campo: Desarrollo e Innovación Educativa por la UPN-Morelos. Se desempeña como docente en los niveles básico, medio superior y superior dentro del sistema educativo nacional público y privado. Entre sus publicaciones recientes está "El indígena mexicano: la interpretación biotipológica (1940-1960)" en coautoría con Gustavo Adolfo Enríquez Gutiérrez en Anuario Mexicano de Historia de la Educación (2018). Correo electrónico: simplementemauricio@gmail.com

(1) https://orcid.org/0000-0002-8942-1121

Historial editorial

Recibido: 03-abril-2020

Aceptado: 18 -junio-2020

Publicado: 21-julio-2020

ISSN-e: 2594-2956 
Corporalidad ciudadana y subjetivación escolar en México (1940-1950): la biotipología de José Gómez Robleda

\section{Resumen}

El artículo forma parte de la investigación: El proyecto educativo de José Gómez Robleda a mediados del siglo XX en México. Esta investigación ha generado tres líneas de análisis a partir del cuerpo: ciudadanía, masculinidad y la educación de los anormales. El presente texto explora la relación entre corporalidad ciudadana y subjetivación escolar mexicana de mediados del siglo XX, en la biotipología de José Gómez Robleda. Este académico fue médicopsiquiatra, funcionario de la Secretaría de Educación Pública (SEP) e investigador en la Universidad Nacional Autónoma de México (UNAM). Metodológicamente, se interpreta la articulación de los conceptos de cuerpo y ciudadanía, desde la biotipología de José Gómez Robleda; concretados en la escuela a fin de formar la mexicanidad de los educandos. Los principales hallazgos del trabajo son: I) La ciudadanización de los mexicanos a mediados del siglo XX, se pensó desde los ejes: individual, social y corporal; como una definición subjetivo-política desde el gobierno mexicano; 2) La escuela se presentó por Gómez Robleda, como un marco de referencia de formación ciudadana en la corporalidad civilizada y 3) Gómez Robleda designó a la escuela, como espacio de subjetivación específica de la ciudadanía en la infancia. El trabajo parte de fuentes primarias, bibliografía especializada y referentes fílmicos y visuales de artistas de la época.

Palabras Clave: biotipología, ciudadanía escolar, cuerpo, eugenesia, hombre medio.
Citizens' Corporality and Scholar

Subjectivation in Mexico (1940-1950): the Biotypology of José Gómez Robleda

\section{Abstract}

The article is part of a larger research project "The Educational Project of José Gómez Robleda in Mid-Twentieth Century Mexico". This investigation has generated three venues of analysis stemming from the body: citizenship, masculinity, and the education of the abnormal. The present text explores the relationship between citizens' corporality and Mexican scholar subjectivation in the mid-twentieth century from the biotypology of José Gómez Robleda. This scholar was a psychiatrist, an official of the Secretaría de Educación Pública (Ministry of Public Education) and a researcher from the Universidad Nacional Autónoma de México (National Autonomous University of Mexico). The articulation of the body and of the citizenship concepts are interpreted through the methodology granted by the biotypology of José Gómez Robleda. These concepts are concretized in school with the objective of forming learners' "Mexicaness". Major findings are: I) The citizenship of midtwentieth century Mexicans was thought from the axis of : the individual, the social and the corporal; as a subjective-political definition from the Mexican government; 2) The school was presented by Gómez Robleda as a reference framework of citizen formation in civilized corporality, and 3) Gómez Robleda designated the school as a space of specific subjectivation of citizenship in infancy. The work is grounded on primary sources, specialized bibliography and visual and film referents from artists of this time.

Keywords: biotypology, scholar citizenship, body, eugenics, average man 
Coorporalité citoyenne et subjectivation scolaire au Mexique (1940-1950): la biotypologie de José Gómez Robleda

\section{Résumé:}

L'article fait partie de la recherche: Le projet éducatif de José Gómez Robleda au milieu du $\mathrm{XXe}$ siècle au Mexique. Cette recherche a généré trois lignes d'analyse du corps: la citoyenneté, la masculinité et l'éducation de l'anormal. Le texte actuel; explore la relation entre la corporalité citoyenne et la subjectivation scolaire mexicaine du milieu du XXe siècle, dans la biotipologie de José Gómez Robleda. Cet universitaire était un médecin psychiatre, un fonctionnaire du Ministère de l'Éducation Publique (SEP) et un chercheur à l'Université Nationale Autonome du Mexique (UNAM). Méthodologiquement; l'articulation des concepts de corps et de citoyenneté est interprétée, à partir de la biotipologie de José Gómez Robleda; concrétisé dans l'école pour former la mexicanidad des étudiants. Les principales conclusions de l'ouvrage sont: I) La citoyenneté des Mexicains au milieu du XXe siècle, a été pensée à partir des axes: individuel, social et corporel; comme une définition subjective-politique du gouvernement mexicain; 2) L'école, a été présentée par Gómez Robleda, comme un cadre de référence pour la formation citoyenne à la corporalité civilisée et 3) Gómez Robleda, a désigné l'école comme un espace de subjectivation spécifique de la citoyenneté dans l'enfance. Le travail part de sources primaires, bibliographie spécialisée et références cinématographiques et visuelles d'artistes de l'époque.

Mots-clés: Biotipologie, Citoyenneté scolaire, Corps, Eugénisme, Homme moyen.
Ciało obywatela $i$ podłoże szkolne w Meksyku (1940-1950): biotypowanie José Gómeza Robledy

\section{Streszczenie:}

Artykuł jest częścią badań: Projekt edukacyjny José Gómez Robleda w połowie $\mathrm{XX}$ wieku w Meksyku. Badania te wygenerowały trzy linie analizy: obywatelstwo, męskość i edukacja niezaakceptowanych. Ten tekst; bada relacje między organem obywatelskim a meksykańską szkołą w połowie XX wieku, w biotypologii José Gómeza Robledy.José Gómeza Robleda był lekarzem psychiatrą, urzędnikiem Ministerstwa Edukacji (SEP) i naukowcem na Narodowym Autonomicznym Uniwersytecie Meksyku (UNAM). Metodologicznie; artykulacja pojęć ciała i obywatelstwa jest interpretowana, z biotypacji José Gómeza Robledy; gdzie szkole sie rozumie jako ksztalcenie obywateli meksykanskich. Główne wnioski z pracy to: I) formowanie obywateli w połowie XX wieku, uwarunkowane bylo subiektywnopolityczną definicja rządu meksykańskiego; 2) szkoła, przedstawiona przez Gómeza Robledę jest jako punkt odniesienia dla szkolenia obywateli w cywilizowanym ciele i 3) Gómez Robleda, wyznaczył szkołę jako przestrzeń formowania obywatelstwa w dzieciństwie. Praca oparta jest na podstawowych źródłach, specjalistycznej literaturze oraz filmowych i wizualnych referencjach artystów tamtego czasu.

Słowa kluczowe: Biotypologia, obywatelstwo szkolne, cialo, eguenika, posrednik. 


\section{Introducción}

En la primera mitad del siglo XX, en México, la ciudadanía estuvo acotada científicamente por el Mendelismo, Darwinismo y Galtonismo ${ }^{\mathrm{I}}$ que clasificaron y definieron el origen social, racial y cultural de las personas; lo cual llevó a la racionalización del nacimiento de niños y niñas: inteligentes, fuertes y sanos. Estas ideas cimentaron el proyecto nacional sobre la calidad de la población en lo social, económico, cultural y educativo (Urías, 2007; Reggiani, 2019; Stern 2002 y 2000). De esta manera, la "ciencia" aseguró el progreso social, el mejoramiento económico y la salud de la población desde la eugenesia ${ }^{2}$ (Reggiani, 20I9). Esta ciencia cobró fuerza como saber objetivo del "buen origen" de las personas a través de medidas sanitarias individuales, sociales y educativas. La eugenesia, distinguió a los individuos por sus características corporales, tratando de lograr la homogeneidad psicosomática constitutiva del ciudadano. Un mexicano saludable, vigoroso y educado como apoyo al progreso del país. El gobierno desarrolló políticas culturales sobre lo mexicano a través de sus diferentes instituciones sociales, económicas, sanitarias y educativas (Stern, 2002 y 2000).

La eugenesia utilizó explicaciones biológicas, en la selección de la normalidad, belleza e inteligencia; implementando medidas higiénicas que favorecieron la salud mental, corporal y social de los mexicanos desde criterios de alimentación, funcionamiento corporal, normas higiénicas y educación (Reggiani, 2019; Suárez, 2005, 2000, 1999; Suárez y Ruiz, 200I). Este marco médico pasó a la educación como higiene escolar, cultura física y desarrollo del tipo normal u hombre medio. ${ }^{3} \mathrm{La}$ intervención psicopedagógica del gobierno concretó estas ideas en las instituciones educativas del país (Granjas, 20II).

En este orden de ideas, José Gómez Robleda fungió como un operador político que usó la biotipología (medidas del cuerpo) como método de medición, clasificación y definición de lo individual a través de la antropología, la medicina, la psiquiatría, la criminología, la educación y la sociología. Estas disciplinas convergieron en lo que Gómez Robleda 
llamó, el hombre medio: "la expresión de la adaptación secular, máxima y perfecta, de la colectividad al ambiente local y, por lo mismo, la expresión también del máximo equilibrio funcional de las partes en el todo individual" (Gómez y D’ Aloja, 1947).

La ciudadanía fue uno de los ejes de la homogenización cultural y política del mexicano mestizo de mediados del siglo XX. Clave de progreso, modernidad y civilidad a partir de la urbanización, la industrialización, la prosperidad y la educación en los mexicanos, a través de sus medidas corporales con las cuales se "alcanzarían los ideales de hombre medio o promedio” (Gómez, 1948).

Metodológicamente, la investigación supuso articular los conceptos de ciudadanía, cuerpo y salud. La ciudadanía como una competencia mostrada y objetivada formalmente (Acevedo y López, 20I2). Un ciudadano, considerado de acuerdo con los derechos y deberes señalados en la Constitución mexicana, las leyes y los reglamentos que se elaboraron en este momento. En el caso de la educación, de acuerdo con el artículo $3^{\circ}$ constitucional: lo democrático, lo popular, lo laico y lo gratuito visibilizaron la ciudadanía en el salón de clases. Por ejemplo, la laicidad implicó una visión científica del mundo y la vida a través de la enseñanza de los contenidos escolares, separados de la interpretación religiosa. Laicidad dominada por la explicación científica del mundo por parte del docente y el aprendizaje de información científica en los estudiantes. Ciudadanía mostrada en la ropa o los rasgos de la nacionalidad (Piccato, 20I2). La forma de vestir del docente le llevó al uso de traje, camisa, corbata y zapatos. En la maestra al uso de vestido, zapatillas y blusa; además del corte de pelo, pulcritud, limpieza y presencia de un cuerpo urbano de un mexicano o mexicana moderno, civilizado y mestizo.

El maestro o maestra representó al hombre o mujer civilizado, laico y democrático; mexicano mestizo concretado en atributos de urbanidad, modos de hablar y actitudes laborales exigidas como servidor del gobierno. Mexicanidad mostrada en el uso de ropa, comida y en las diversiones públicas del docente y en el grupo escolar. 
Ciudadanía en un cuerpo como simbolización sociohistórica, autorizada o reglamentada en las prácticas sociales desde el poder (De Certeau, citado por Vigarello, 1997; Foucault, 2007, 2002 y 1980). El cuerpo del docente mostró la imagen del proyecto dominante del gobierno mexicano en lo civilizado: al hablar, caminar y expresar su visión del mundo. Modernidad de un cuerpo que portó ropa de hombre o mujer, de acuerdo con los criterios culturales de un ciudadano del mundo; ponderado por la narrativa social del gobierno y visibilizado en la vestimenta.

El uso de traje en los hombres, el vestido en las mujeres, los pantalones cortos en niños, las faldas en las niñas y el uso de zapatos; además, de el corte de pelo, el peinado y los cosméticos -de acuerdo con el génerofueron las formas de particularizar estas ideas de lo mexicano. Las diferencias marcadas en el uso de pantalón de vestir, casimir y saco de un profesionista, frente al uso de mezclilla, overol o manta de un obrero o campesino. Un sombrero, un reloj, un portafolio, una pluma o al contrario el morral, la gorra y el lápiz, marcaron las diferencias en la condición social, profesional y cultural de cada uno de los mexicanos.

Un cuerpo de obrero, un cuerpo de campesino o un cuerpo de profesionista implicó cambios en la imagen de lo mexicano, reforzado por la narrativa del cine y la cultura popular a través de la música, los cuentos, las leyendas y los refranes circulados en la vida cotidiana de los mexicanos.

La salud como una estrategia política donde se definió, evaluó y formó a los cuerpos en la primera parte del siglo XX (Agostini, 20I8; Aréchiga, 2007; Gómez-Dante y Frenk, 2019; Gudiño-Cejudo, 2013 y 2008; Melchor, 20I8). La salud significó un atributo de la capacidad física del cuerpo para el trabajo de obreros y campesinos que sostendrían el desarrollo del país. Salud que se expresó en sus condiciones sociales a través de la reducción de la mendicidad, la delincuencia, la prostitución en favor de un ciudadano mexicano productivo, responsable, inteligente y sano. 
Ciudadanía que promovió la educación de los anormales: eliminar el retraso escolar, apoyar a los débiles físicos (ciegos y sordos), los lisiados (amputados y parapléjicos) y a los anormales mentales (imbéciles, idiotas, débiles mentales y anormales morales). Una salud que apostó a la educación de la infancia como futura ciudadanía y cimiento del crecimiento social, económico, cultural y político de la nación. Salud que significó la construcción de un cuerpo mexicano capaz, moderno y progresista; en un país industrial, urbano y educado.

El presente artículo se organiza en tres apartados, que buscan dar cuenta de la forma en que las políticas sobre el cuerpo definieron la subjetividad ciudadana de los mexicanos (hombres y mujeres) a través de la escuela, a mediados del siglo XX: i) La corporalidad ciudadana del mexicano: la mirada médica y social, ¿qué tipo de cuerpo buscó desarrollar la medicina en los mexicanos de mediados del siglo XX?; 2) La interpretación biotipológica: la construcción política-subjetiva del cuerpo, ¿cómo se construyó científicamente el cuerpo del mexicano de mediados del siglo XX? y, 3) La escuela formadora de unidad nacional: la corporalidad escolar ciudadana, ¿qué cuerpo buscó formar la escuela en los futuros mexicanos a través de la unidad nacional?

\section{La corporalidad ciudadana del mexicano: la mirada médica y social}

La ciudadanía mexicana, en la primera mitad del siglo $\mathrm{XX}$, estuvo pensada desde el locus cultural mestizo, a través de los espacios institucionales creados por los gobiernos posrevolucionarios en las escuelas públicas. Las instituciones educativas de primaria se convirtieron en lugar de concreción de las políticas gubernamentales. La institución escolar básica inculcó la visión científica del mundo, el progreso y la unidad nacional a través de un sólo país (Gudiño- Cejudo, 2008). En este sentido, se construyó la idea de ciudadanía desde las dimensiones social e individual-corporal. Estas dimensiones, fundamentaron las ideas de lo mexicano, acorde con la imagen y concepción política del sujeto moderno-mestizo, apoyada de la ciencia 
del momento, la eugenesia y concretada por la biotipología (Gómez, I948).

El predominio del proyecto nacional mestizo se elaboró desde finales del siglo XIX. Contribuyó a la propagación de estas ideas, la postura de Pedro Henríquez Ureña en Latinoamérica. En México, los trabajos del antropólogo Manuel Gamio y del abogado, político, filósofo y educador José Vasconcelos (Maíz, 2008 y Reggiani, 2019). Ambos fueron los promotores del nacionalismo mexicano a través de la unificación cultural, política y educativa. Los problemas sociales y educativos de las dos primeras décadas del siglo XX; establecieron para el gobierno mexicano una estrategia de reconstrucción y desarrollo donde predominó la eugenesia, como herramienta de interpretación e intervención sobre la población, a fin de buscar su mejoramiento en los cuerpos de los mexicanos: hombres, mujeres, jóvenes e infantes.

La eugenesia colocó el discurso higiénico y médico como instrumento de modificación de los problemas de salud, tanto en el terreno individual como en el social. La higiene escolar y la mental, fueron las formas a través de las cuales se buscó cambiar las condiciones insalubres de los cuerpos de las personas e inculcó el progreso occidental de la modernidad. Esta tarea se apoyó en el discurso médico, antropológico, legal y educativo (Reggiani, 2019). La educación fue la portadora de la formación de la salud corporal en la población y sostén de su mejoramiento físico, social y cultural.

Entre 1920 y 1940 se desarrollaron políticas de salud a través de la "dictadura sanitaria", estrategia cuya finalidad fue sacar a la población del país del atraso social, usando la educación sanitaria y la propaganda higiénica sobre el cuidado de los cuerpos. La dictadura sanitaria, promovió un enfoque civilizatorio de la modernización nacional, a través del cuidado físico, el ejercicio y la alimentación (Aréchiga, 2007). En este tenor, las estadísticas del gobierno del Distrito Federal, sobre las principales enfermedades transmisibles -registradas entre $1925 \mathrm{y}$ I928- fueron: difteria, escarlatina, erisipela, fiebre puerperal, fiebre tifoidea, gripa, lepra, meningitis, oftalmía purulenta, sarampión, tifo, 
tos ferina, tuberculosis, varioloide y viruela (Agostini, 2018). La medicina y la eugenesia convirtieron a las enfermedades en un mal a combatir, usando la higiene como herramienta de orden, civilidad y progreso, a través de los cuerpos sanos.

De I9IO a I95I se realizaron distintas campañas de Salud Pública, por ejemplo: Campaña nacional antivariolosa en 1917; Campaña nacional contra la fiebre amarilla en I92I; Campaña contra el paludismo en I926; Campaña contra la lepra en I930; Campaña contra la oncocercosis en I932; Campaña contra la tuberculosis en I934; Campaña contra el cáncer en I94I; Campaña contra las enfermedades venéreas y contra el bocio en I943 y Campaña contra la poliomielitis en I95I (Gómez-Dante y Frenk, 2019). En este periodo se observó la preocupación por atender la viruela, fiebre amarilla, paludismo, lepra, ceguera de los ríos, tuberculosis, cáncer, enfermedades venéreas, bocio y poliomielitis; lo cual indica los males que aquejaron los cuerpos de mexicanos y mexicanas a mediados del siglo $\mathrm{XX}$ y que se concentrados en las comunidades rurales, en la creciente población de obreros y trabajadores que aumentó después de la Revolución mexicana. ${ }^{4}$

En I922, en el Distrito Federal, nació la Escuela de Salubridad con un carácter público, apoyada por el gobierno mexicano. Esta institución médico-educativa capacitó a estudiantes de medicina, enfermeras y asistentes sociales a fin de trasladarlos a comunidades rurales para brindar atención médica y realizar orientaciones educativas de carácter preventivo en las comunidades (Gudiño-Cejudo, Magaña-Valladares y Hernández, 2013). Tres años después -en I925- se comenzó a construir el edificio del Departamento de Salud Pública, hoy Secretaría de Salud Federal (Gómez-Dante y Frenk, 20I9).

La Secretaría de Educación Pública (SEP) creó el Departamento de Psicopedagogía y Médico Escolar (DPyME) en 1925 y funcionó hasta 194I. Este departamento llevó a la práctica las ideas de la medicina (higiene) y buscó solucionar los problemas de retraso escolar en las escuelas. La eugenesia, a través de la medicina, guió el trabajo psicopedagógico de este departamento y generó investigación; realizó 
la evaluación e intervención psicopedagógica de la infancia escolar, sobre todo de la anormal.

El Departamento de Psicopedagogía y Médico Escolar, funcionó con siete actividades: I) Servicio de faidografía, 2) Servicio de paidotécnia y organización, 3) Servicios de escuelas especiales, 4) Servicio de psicometría, 5) Servicios de Orientación profesional, 6) Servicios de higiene mental escolar y clínica de la conducta y 7) Servicios generales: centro de divulgación e intercambio, biblioteca y centro de propaganda (Negrete, 20I6).

Este cuadro médico-educativo mostró la forma de interpretar la higiene mental y escolar de niños y niñas, a través de su medición, evaluación e intervención. Con ello se detectaba a la infancia anormal que requería atención en su desarrollo (Negrete, 20I6). El eje de este trabajo fue el retraso escolar y la forma en que este repercutía en el mejoramiento de niñas y niños. El DPyME no sólo buscó solucionar los problemas de retraso escolar, sino también colaboró en la realización de investigaciones antropométricas, biológicas y psicotécnicas de indígenas, obreros, escolares y deportistas mexicanos (Reggiani, 2019), por ejemplo: Características biológicas de los escolares proletarios (Gómez, 1937) y Deportistas (Gómez, 1940).

En 1930, la Sociedad Eugénica Mexicana se constituyó como un organismo especializado en el estudio racial de la población mexicana (Stern, 200o). Esta sociedad estableció un modelo objetivo de la ciudadanía, a partir de los rasgos políticos, biológicos, psicológicos y educativos del cuerpo del mexicano moderno. De igual modo, la higiene social se encargó de implementar medidas sanitarias a la 140 población, a través de campañas de salud dirigidas por médicos, en zonas rurales y marginadas. Estas acciones estuvieron orientadas a promover la modernización del país, el mejoramiento racial y el avance de la ciencia, materializando el progreso a través de la medicina y el cuerpo. Este marco político convirtió a la salud en "dictadura sanitaria" (Lara, 20I0). En este sentido, se buscó modificar la conducta de las madres de familia sobre la higiene corporal-familiar, así como de la 
población, a fin de generar conciencia sobre la importancia de la salud en la familia mexicana.

Los gobiernos posrevolucionarios plantearon la reconstrucción nacional, a través de la reingeniería social de los mexicanos y el fortalecimiento de su salud. En otras palabras, las políticas sanitarias buscaron la cimentación de un país sano, numeroso y productivo, a través de dos vías: I) Combate a las enfermedades contagiosas y 2) El mejoramiento racial de la población (Aréchiga citado por Melchor, 20I8). Durante las primeras décadas del siglo $X X$, la fundación Rockefeller y la Universidad Johns Hopkins fomentaron la investigación científica y médica en el país (Melchor, 2018). Estas acciones convirtieron a México en un laboratorio social de combate a las enfermedades contagiosas y en un espacio de indagación médica del gobierno norteamericano.

Un ejemplo de investigación sobre la eugenesia en México ocurrió en el año de 1936. Una expedición francesa llegó al país, auxiliada del Departamento de Psicopedagogía y Medico Escolar, a fin de estudiar a los otomíes. La investigación indagó el origen de la población, tomando en cuenta la puericultura, la fisiología y la nutrición (Vargas, 20I5). Este estudio fue financiado por la Sociedad de Biotipología francesa, cuyo propósito fue obtener mediciones fisiológicas y psicológicas de los otomíes, y fue apoyado por el Instituto de Biología de la Universidad Nacional Autónoma de México (Vargas, 2015).

La eugenesia dictó las pautas en la explicación e intervención social de la población. Desde su punto de vista y apoyada en la biología moderna, buscó resolver los problemas sociales de los mexicanos a través del mejoramiento de la vida corporal y su regeneración racial. La biología tomó el control político al dictar normas a la existencia y la salud, pasando del campo del saber médico a la intervención personal (Foucault, 2007).

La medicina mexicana transformó su carácter moral por uno social. Combinó factores culturales, sociales y políticos al atender la salud de 
la población de contextos desfavorecidos (Rodríguez y Rodríguez, 1998). En este sentido, la política de salud buscó mejorar las condiciones evolutivas de la población e indagar sobre: "el conjunto de procedimientos de terapia o sistemas terapéuticos aplicados a cuerpos sociales para prevenir, encauzar y remediar los desajustes o desorientaciones que en su marcha evolutiva pueden presentarse" (Jiménez, 1938, p. 442).

Durante el Cardenismo (1934-1940) se estableció el plan sexenal sanitario del país y las tareas de los médicos. Entre las acciones prioritarias fueron: en 1934, la creación del Instituto de Salubridad y Enfermedades Tropicales; en 1936 se fundaron los Servicios Médicos Ejidales Cooperativos y se implementó de manera obligatoria el Servicio Social de los Pasantes de Medicina; en 1937, el Departamento Autónomo de Asistencia Social Infantil; en 1938, la Secretaría de Asistencia y la Escuela Superior de Medicina Rural, además, la promulgación de su Estatuto Jurídico (Suárez y López Guazo, 1999).

La Revista Eugenesia, portavoz de las ideas eugénicas mexicanas, señaló en su editorial de 1940, que los problemas de la infancia en México eran desnutrición y taras mentales. Promovió una política educativa sobre el desarrollo prospectivo de la ciudadanía infantil (Suárez y López Guazo, 1999). Las campañas eugénicas procuraron incidir en la futura salud de la población por medio de su mejoramiento físico, intelectual y moral (Saade, 2004).

En este contexto, José Gómez Robleda se interesó en la constitución psicofísica del ciudadano mexicano u hombre medio. Investigó, describió, diseñó e instrumentó proyectos y después indicó estrategias

142 educativas. De esta manera, la ciudadanía -desde su propuesta científico-política- partió de caracterizar biotipológicamente al mexicano y sugerir mejoras en la higiene-corporal de escolares, proletarios, deportistas e indígenas. El modelo de corporalidad ciudadana contempló al hombre, heterosexual, citadino, de clase media, y a la mujer citadina, heterosexual, de clase media. 
La tarea primordial, en Gómez Robleda, fue clasificar y formar al mexicano de acuerdo con los cánones de la ciencia y del interés político, contenido en el proyecto nacional mestizo. Los rasgos de civilidad fueron visibilizados en hombres y mujeres de ese momento, a través del cuerpo. Basta decir que las medidas corporales para hombres y mujeres fueron como se observa en la tabla I.

Tabla I. Constitución media de hombres y mujeres en México en 1948.

\begin{tabular}{|c|c|c|c|}
\hline \multicolumn{2}{|c|}{ Mujer } & \multicolumn{2}{|c|}{ Hombre } \\
\hline Índice torácico & $5.97 \mathrm{~cm}$ & Índice torácico & $7.48 \mathrm{~cm}$ \\
\hline $\begin{array}{l}\text { Índice } \\
\text { abdominal }\end{array}$ & $\mathrm{I} 4.64 \mathrm{~cm}$ & $\begin{array}{l}\text { Índice } \\
\text { abdominal }\end{array}$ & $\mathrm{I} 5.57 \mathrm{~cm}$ \\
\hline $\begin{array}{ll}\text { Índice } & \text { del } \\
\text { tronco } & \end{array}$ & $20.86 \mathrm{~cm}$ & $\begin{array}{l}\text { Índice } \\
\text { tronco }\end{array}$ & $23.05 \mathrm{~cm}$ \\
\hline $\begin{array}{ll}\text { Índice } & \text { de } \\
\text { miembros } & \end{array}$ & $\mathrm{I} 23.63 \mathrm{~cm}$ & $\begin{array}{ll}\text { Índice } & \text { de } \\
\text { miembros } & \end{array}$ & $\mathrm{I} 34.68 \mathrm{~cm}$ \\
\hline Peso & $51.8 \mathrm{~kg}$ & Peso & $53.25 \mathrm{~kg}$ \\
\hline Estatura & $\mathrm{I} 54.30 \mathrm{~cm}$ & Estatura & I66.I7 cm \\
\hline
\end{tabular}

Fuente: Basado en Gómez (1948).

Para el propósito trazado, fue de vital importancia la educación a través de la higiene. Una educación higiénica a través de la educación física, la salud corporal, la alimentación, el vestido, la civilidad y la formación del pensamiento científico. Esta tarea se promovió a través del cuerpo mestizo con valores de salud física, moral y social. Estas acciones político-educativas se dirigieron al modelaje psicofísico de obreros, indígenas, campesinos y clase media. Tareas formativas concentradas en la identidad corporal de mexicanos fuertes, sanos e inteligentes; indicadas en el hombre promedio o mestizo (Padilla, 2009; Urías, 2007 y Suárez y López Guazo, 1999).

Una narrativa que contó las dificultades de la formación del hombre medio a través de la medicina fue la película: El rebozo de Soledad, de 
Roberto Gavaldón (1952). La cinta mostró la paradoja que enfrenta el médico comunitario, Alberto Robles (Arturo de Córdova): entre dedicarse al cuidado de pacientes en el medio urbano o curar los males de la comunidad rural donde realizó su servicio social -Santa Cruz-, oprimida por el cacique local.

El rebozo de Soledad, según Néstor Ramírez Vega (20I4), tocó dos puntos: el cuidado en las comunidades y la labor social del médico. La atención en la comunidad rural corrió a cargo de la mujer. La labor del médico trastocó el interés por las enfermedades y se dirigió a la comunidad. El rebozo, fue el objeto que contó la preocupación, y el respeto del hombre tanto a la mujer como a la tierra. Esto se vio reflejado en el diálogo que estableció Soledad (Stella Inda) con Roque (Pedro Armendáriz):

- Usted no comprende que soy mujer y una mujer es como la tierra. Que el hombre no debe ofenderla. No le pareció bien que David se metiera a las malas a su tierra, ¿verdad? Pero sí haya bien querer mujer que no le pertenece porque es como si fuera tierra de otro, usted la quisiera para su disfrute. Quiere comprarla con un rebozo.

- Yo no quise comprarte Soledad. Dijiste que te gustó y te lo traje.

- Guárdeselo, no me servirá. El rebozo, la mujer y la tierra deben ser de respeto pal hombre. ¿Qué no lo sabe? Pero usted, a cómo querer rebozarme, a malas, querer darme rebozos sin la bendición de Dios. No haga ofensa a la mujer, que no quiera hacer a su propia tierra (Revueltas citado por Ramírez, 20I4, párr. 9-II).

La tierra y la mujer fueron aspectos esenciales en la diligencia hacia los 144 otros en un país eminentemente rural; donde se requería producir alimentos y proteger a la prole. Un país que necesitaba cuerpos sanos y fuertes en la mayor parte de su población: campesinos y obreros. El papel del médico era fundamental; el personaje del padre Juan (Domingo Soler), lo retrató claramente cuando señaló: "Este libro está escrito para ti, Alberto. Es parte de nuestra vida, un fragmento de lo que vivimos. Tú como sacerdote de cuerpos, yo como médico de almas. 
Juntos luchamos por la misma causa: aliviar el sufrimiento de nuestros semejantes y enseñarles que no existe nada más sagrado que el respeto a la dignidad humana" (Revueltas citado por Ramírez, 20I4, párr. I7). El médico fue el sacerdote de cuerpos, mejorando esta "debilidad socialcorporal" a fin de transformar a los mexicanos (hombres y mujeres), en mestizos fuertes y sanos, desde los ideales del hombre medio, que serían utilizados para la formación escolar de la infancia como futura ciudadanía mexicana.

\section{La interpretación biotipológica: la construcción político-subjetiva del cuerpo}

El cuerpo de mediados del siglo XX se convirtió en un portador de calidad ciudadana. El cine, la radio, la propaganda política, y la educación recalcaron sus atributos: sano, bello y civilizado. La pintura de Saturnino Herrán, a finales del Porfiriato, colocó la belleza del cuerpo mestizo de hombres y mujeres en una interfaz entre lo indígena y lo español. Su pintura situó rostros indígenas en cuerpos occidentales de hombres fuertes o mujeres decididas. Este pintor enfatizó lo mestizo en la tez, como en el cuerpo. Esta corporalidad se mostró, por ejemplo, en El rebozo y Nuestros dioses antiguos (Herrán, 1916). La primera retrató a una mujer mestiza desnuda, sentada sobre una cama. En Nuestros dioses antiguos presentó los dorsos desnudos de cinco hombres, con rostros indígenas y cabellos cortos castaños. Estas expresiones corporales remarcaron el cuerpo mexicano con rasgos modernos, a través del mestizaje en cara, dorso, abdomen, brazos y piernas.

El cuerpo recordó el pasado occidental a través de imágenes griegas e hizo patente la realidad indígena en los rostros. En otras palabras, mezcló la piel y la cultura blanca europea en los rasgos corporales; y las culturas indígenas en las caras, a fin de recrear al nuevo mexicano de finales del siglo XIX y principios del XX. El cuerpo se observó como un portador de identidad mestiza en una nueva modernidad, desde la mexicanidad en el mundo occidental (Mantilla, 20I9). 
Durante la primera parte del siglo XX, los rasgos mestizos en cuerpos de hombres y mujeres mexicanos se encarnaron a través del cine, la fotografía, la pintura y las narrativas de los íconos de hombres y mujeres de la época. Sobresalen las imágenes de actrices y actores como María Félix, Dolores del Río, Elsa Aguirre, Blanca Estela Pavón, Katy Jurado; además de Pedro Armendáriz, Pedro Infante, Jorge Negrete, Luis Aguilar, Abel Salazar y Antonio Badú. Cuerpos de mujeres y hombres que resaltaron el mestizaje y la belleza de la mexicana y el mexicano moderno, a través de escenas en el campo, la ciudad y la vida moderna de la Ciudad de México.

La pintura mural expuso al mestizo (hombre o mujer), como la imagen viva de la mexicanidad nacional, progresista y moderna. Las pinturas como: Prometeo (1930) de José Clemente Orozco; Muerte al invasor (1942) de José Alfaro Siqueiros; Sueño de una tarde dominical en la alameda central (1947) de Diego Rivera y América (1956) de Rufino Tamayo. Instalaron el mestizaje de los cuerpos en murales, exponiendo públicamente el imaginario social de belleza, salud, fuerza y armonía; sobre todo, la seguridad de la nueva mexicanidad. Se estableció una red de significados sociales sobre la civilidad y el progreso de la corporalidad mestiza. En este escenario, Gómez Robleda clasificó y definió la calidad ciudadana de los cuerpos y construyó un modelo de ciudadano mexicano (tabla 2).

La clasificación corporal de Gómez Robleda estableció criterios biotipológicos (medidas entre cuerpos) y biométricos (medidas en el cuerpo), fundamentalmente en indígenas (Gómez, 1947). En este sentido, realizó un estudio corporal de los grupos humanos, integrando criterios raciales de indígenas (zapotecas y tarascos) y de otros grupos 146 sociales: obreros, campesinos y deportistas; determinando la correspondencia del cuerpo de una persona y un grupo, al estatus de normalidad/anormalidad de la mexicanidad. 
Tabla 2. Tipología de la normalidad y anormalidad del cuerpo del mexicano, 1943.

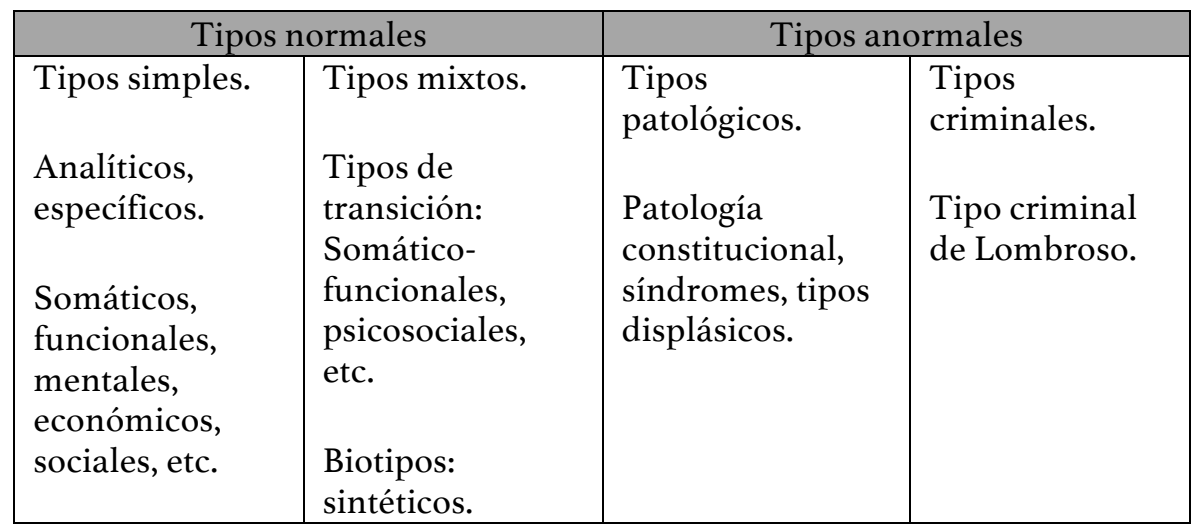

Fuente: Basado en Gómez (1943).

De este modo, Gómez Robleda definió:

El individuo normal corresponde exclusivamente a una abstracción pura, carente de realidad objetiva. Los individuos que existen siempre quedan afectados por anormalidades de importancia variable que, cuando imposibilitan la vida en sociedad e impiden o alteran las funciones de adaptación, dan origen a los que propiamente deben considerarse como estados patológicos (Gómez, 1937, p. 8).

La mirada productiva en el cuerpo apareció en Gómez a través de la adaptabilidad: buena salud y fuerza. El individuo normal carecía de alteraciones patológicas y funcionales. Los indígenas eran anormales por misteriosos, singulares, fuertes y práctico-realistas (Gómez, 1948). Bajo el adjetivo de "misteriosos" y "practico-realistas", Gómez pensó al indio con actitudes "anormales-femeninas". Lo presentó desde su singularidad anormal diferente, una imagen que buscó homogeneidad racial y segregación social. Ambivalencia en la interpretación (homogeneidad/segregación) que lo acompañó en el estudio de los 
zapotecos (Gómez, 1949). En este trabajo, los zapotecas fueron los guardianes de los secretos del hombre, la vida, el mundo y el universo; sin embargo, vivieron en el pasado siempre presente. Los indígenas denotaron una visión cultural y un destino, pero connotaron un atraso anormal anclado en el ayer. Un pasado que les impidió avanzar hacia la modernidad industrial y al progreso científico. Prueba palpable fue su cuerpo: "...ha sabido resistir, sin extinguirse, ha siglos de adversidad..." (Gómez, I949, p. 4II).

En cuanto a la fisiología-anormal zapoteca destacó su debilidad ósea, lentitud cardiaca, delgadez, baja estatura y piel morena. Máquina corporal deficiente que consumía rápidamente lo que obtenía. Los rasgos físicos, el apego al pasado, su sentido práctico-realista, convirtieron a los zapotecas en individuos tipológicamente "inferiores" (Gómez, 1949). Al compararlos con los individuos de clase media urbana, reconoció su "debilidad social", como fruto de sus condiciones de vida.

De igual modo, en los indios tarascos, Gómez hizo un hallazgo "anormal” similar: “...zurdería por concepto de la agudeza táctil, fuerza muscular deficiente, ligera bipotensión arterial, tendencia hacia la vogotonía revelada por las pruebas de Martinet, de Strauss y de las cinco tomas sucesivas de la tensión arterial y, también, por la lentitud del pulso, vagotonía revelada por la prueba densiométrica" (Gómez, I943, p. 328). Estas mediciones corporales le permitieron a Gómez determinar la inestabilidad fisiológica del indio en lo cardiaco, respiratorio y motriz.

Gómez agregó a las “anormalidades” físicas: “carácteres antropológicos de las clases pobres" aún más: "escaza altura de la frente, cráneo frontal menos desarrollado, perímetro de cráneo deficiente o peso corporal absoluto inferior, estatura baja (menor que la de los ricos)" (Gómez, I943, p. 347). Estas ideas sobre el indígena mexicano, le llevaron a su tipificación corporal como: "minimizada y deficiente". El cuerpo indígena fue visto como atrasado, inadaptado, anormal, en relación con el cuerpo de europeos y norteamericanos. 
El análisis de Gómez se enfocó en la descripción de las características normales-individuales de la clase media; basado en la antropometría de Kretschmer, Niceforo, Strachey y Viola-Barbará (Gómez, I948). En el caso de la mujer señaló su fisiología y características somáticas con aptitudes práctico-realistas al igual que las del indio. Los rasgos somáticos se empataron con el temperamento y la orientación en la vida práctica (Gómez, 1948). De este modo, el trabajo de hombres y mujeres fue restringido por su división sexual y sus condiciones corporalesnormales: fuerza, vigor, resistencia y tenacidad. Puntualizó lo femenino con la neurosis histérica y la locura maniacodepresiva, términos psiquiátricos de la constitución psíquica del momento. La ansiedad, los cambios frecuentes y la bipolaridad fueron actitudes asociadas a lo femenino, además de una figura redonda distinta a la masculina.

En relación con el cuerpo de los hombres, los designó como: "seres planos", por sus características corporales, le llevó a establecer ciertas particularidades como "intersexualidad, temperamento feminoide, esquizotípico y neurótico-obsesivo” (Gómez, 1948, pp. 20-2I). Estas designaciones condicionaron la clasificación de su cuerpo e influyeron en sus peculiaridades psíquicas y sexuales, así como la visión teóricoidealista masculina, donde se enfatizó un tipo de pensamiento más centrado y menos visceral. Esto se complementó con el modelo ideal del hombre medio propuesto por Gómez:

El hombre medio, nuestro, es ingenioso y muy inteligente, y si padece de un aparente miedo a pensar es porque le asusta el presentimiento de lo que podría, magníficamente elaborar la ciencia que le daría técnica para la industria y seguridad de vida a la vez que ánimo resuelto para librarse de su exagerado amor a la misteriosidad del mundo y de la vida. Allí, donde se muestra más rabiosamente fanático, se oculta su máxima debilidad y la mayor mentira de su existencia (Gómez, I948, p. 74-75).

El hombre medio-normal se sustentó en la ciencia biotipológica y en el desarrollo industrial; describiendo su inteligencia como superior al promedio, dotado de ingenio y buen ánimo. Estas condiciones se 
presentaron como criterios de formación ciudadana-corporal, nacionalista y racionalista. Gómez determinó roles sexuales y sociales, considerando que: "el hombre que trabaja tiene responsabilidades y lucha, y por la otra, la mujer cuya vida está íntegramente ocupada por la maternidad en toda su complejidad" (Gómez, 1940, p. 290). Estos roles impactaron en el modelo de ciudadanía-corporal en lo laboral y sexual. El hombre como trabajador y la mujer como madre de familia. Una subjetividad-normal atrapada bajo la coraza de la masculinidad y la feminidad de la época.

Estas ideas se vieron reflejadas en el ambiente social que privó, a mediados del siglo XX en México, a través de la película: Una familia de tantas de Alejandro Galindo (1948). La narrativa del filme mostró cómo una familia de clase media en el Distrito Federal (Ciudad de México); fue confrontada en sus valores generacionales. La discrepancia sobre los valores familiares se desató tras la llegada de un vendedor de electrodomésticos, Roberto del Hierro (David Silva), que cuestiona estos valores y la supuesta concordia entre los integrantes de la familia Cataño. La narrativa cinematográfica dio cuenta de las diferencias entre dos generaciones de la clase media: la restrictiva del padre y la liberal del vendedor de electrodomésticos.

Los roles sexuales y laborales, propuestos por José Gómez Robleda, comienzan a tambalearse por los cambios sociales y la presión cultural norteamericana, que tocó las cuerdas sensitivas del nacionalismo mexicano, como lo retrató José Emilio Pacheco, en Las batallas en el desierto:

Mientras tanto nos modernizábamos, incorporábamos a nuestra habla términos que primero habían sonado como pochismos en las películas de Tin Tan y luego insensiblemente se mexicanizaban: tenquíu, oquéi, uasamara, sherap, sorry, uan móment pliis. Empezábamos a comer hamburguesas, páys, donas, jotdogs, malteadas, áiscrim, margarina, mantequilla de cacahuate. La cocacola sepultaba las aguas frescas de jamaica, chía, limón. Únicamente los pobres seguían tomando tepache. Nuestros padres 
se habituaban al jaibol que al principio les supo a medicina. En mi casa está prohibido el tequila, le escuché decir a mi tío Julián. Yo nada más sirvo whisky a mis invitados: Hay que blanquear el gusto de los mexicanos (Pacheco, I992, p. 3)

Un cuerpo moderno en una realidad distinta, replanteó las nuevas formas de subjetividad-normal en los cuerpos. Fue el hacer de hombres y mujeres, las otras formas de ser mexicanos y mexicanas que aparecieron, las que hicieron tambalear estos ideales. En este plano, José Gómez Robleda buscó crear ese hombre y esa mujer que requería el país: normal, productivo, civilizado, progresista, educado y heterosexual, a través de la clase media, a fin de mejorar el cuerpo de obreros, campesinos e indígenas, a través de la biotipología basada en la eugenesia. Estas ideas se colocaron en las escuelas como sostén del cuerpo-normal civilizado y de la ciudadanía moderna mexicana.

\section{La escuela formadora de unidad nacional: la corporalidad escolar ciudadana}

En 1947, Emilio “El indio” Fernández, dirigió la película Río escondido. Esta cinta narró la forma en que la maestra Rosaura Salazar (María Félix), por encargó del presidente de la república -pese a sus males cardiacos- dejó la ciudad y se trasladó a Río Escondido. En este pueblo comienza su labor como maestra rural. Rosaura puntualizó la instrucción, autonomía y firmeza en la enseñanza escolar mexicana y al llegar al pueblo, descubrió el dominio cacical de Don Regino Sandoval (Carlos López Moctezuma). Un fragmento de la cinta retrató esta idea:

Les prometí hablarles de un gran mexicano, uno de los más grandes mexicanos, uno de los más ilustres del mundo que ha sido y sigue siendo a través de los tiempos ejemplo de fe y patriotismo. Ese hombre se llamó: "Benito Juárez" y era indio como ustedes. Nació en un pueblo apartado de la civilización como: "Río Escondido", y hasta los doce años aprendió a leer y escribir. Este indio, este 
hombre, llegó a ser Presidente de la República. Defendió a su patria de los invasores y luchó hasta su muerte por la regeneración de los de abajo: "los pobres, los analfabetas, los oprimidos". Enfrentó a los malos mexicanos que los tenían convertidos en esclavos... (Fernández, 1947, 2.24 min.).

La película captó la ideología de la unidad nacional mexicana. La escuela se pensó como un espacio formativo ciudadano en lo físico, individual y social. La imagen de la maestra mostró a través de su vestido largo, el peinado con trenzas y su presencia física; la salud y la corporalidad mestiza como muestra de la mexicanidad dominante. La estampa se reforzó a través de su voz timbrada y clara. En lo individual, la maestra enmarcó la formación moral de los estudiantes, las normas y cuidado de sus cuerpos. En lo social, fomentó al buen ciudadano como trabajador, productivo, cumplido, responsable, limpio y sano.

En este contexto, la educación higiénica, tuvo como objetivo: "la enseñanza de los principios fundamentales de metodología y psicopedagogía que se emplean en la instrucción del público sobre medicina e higiene general, medicina preventiva y salubridad" (Anuario de la Escuela de Salubridad e Higiene, citado por Magalla y Gudiño, 20I2, p. 3I). Esta educación higiénica partió tanto de métodos de educación individual, como hacia la comunidad, además vinculó a las autoridades escolares en el mejoramiento de la salud. El propósito de la educación higiénica fue definir el material idóneo; así como la estrategia de difusión de salud adecuada a la población.

En relación con la educación, esta se constituyó en eje de formación corporal-ciudadana, al buscar superar los problemas evolutivos, reconocer el retraso escolar, valorar las capacidades mentales, sociales y fisiológicas de la población. La escolaridad, en la Unidad Nacional, significó seguir los sonidos dominantes del contexto nacional y promover el progreso social-corporal, como señaló Gómez:

Ser analfabeto, en el mundo de nuestros días, significa permanecer en una grave situación de inferioridad social. Para 
expresarlo con toda sinceridad, de nuestro país debe decirse que está tan poco evolucionado, que a la mitad de su población no le es necesario ni leer, ni escribir para ganarse la vida.

En general se manifiestan muchas deficiencias -cuantitativas todas, indiscutiblemente- que están en relación íntima con el grado de pobreza nacional; si a tal circunstancia, que es un accidente en la evolución del pueblo, se le ha de llamar inferioridad, podremos decir entonces que somos inferiores por pobres, no por mexicanos (Gómez, 1948, p. 50).

La educación aseguró elementos básicos para leer, escribir, resolver problemas, conocer la naturaleza, la sociedad y la ciencia. Gómez asoció analfabetismo con pobreza. Síntomas de inferioridad socio-corporal: "somos inferiores por pobres, no por mexicanos", situación que definió la corporalidad ciudadana al estar determinada por las condiciones de vida. De este modo, a la mayoría de los mexicanos se les ubicó en inferioridad somática, lo que llevó a la necesidad de ser educados a partir de la higiene escolar.

La situación de inferioridad social-corporal fue expresada en la película: Los olvidados de Luis Buñuel (1952). La historia mostró la pobreza en el Distrito Federal, a través de la vida de un grupo de niños en un barrio marginal de la ciudad. Este relato contrastó con la industrialización y el crecimiento económico propuesto a la nación. En la película, la pobreza se asoció al crimen, la injusticia y el abandono. La secuencia fílmica reflejó un México que no alcanzó el anhelado progreso, una nación que requería una estrategia educativa para alcanzar el desarrollo y el mejoramiento del cuerpo de los mexicanos.

Gómez (1937) apuntó en su investigación sobre los escolares proletarios, lo siguiente: "Las informaciones de carácter económico-social que reunimos evidencian de manera incuestionable, el estado de pobreza de los niños y sus familiares... se opone a lo que con toda propiedad podría llamarse la «salud social»" (p. 5I). La salud socio-corporal tuvo su etiología en la pobreza y su profilaxis fue la educación higiénica. 
La salud-corporal de los proletarios tocó la vivienda, la distribución de muebles, la ropa, la moral y sus diversiones. La escuela formó, pero el contexto social determinó la condición del cuerpo, su salud y calidad ciudadana. Los portadores de civilidad fueron mostrados en la casa, los objetos de uso, la ropa y la diversión. Estos portadores fueron los reflejos contrastantes de la civilidad, el progreso y la modernidad. La mirada de Gómez fue dura y su interpretación no tuvo concesiones al afirmar:

La pobreza, la incultura, el fanatismo, la enfermedad, el hambre, el trabajo fatigante, el alcoholismo, etc., son factores que provocan la inferioridad (en el más amplio sentido del término), dejan a este grupo humano en las condiciones más propicias para la explotación (Gómez, 1937, p. 5I).

Desde su posición, la inferioridad del cuerpo se asoció con la dependencia a la pobreza: la incultura, el fanatismo, la enfermedad, el hambre, el trabajo fatigoso y el alcoholismo. La ciudadanía escolar, estuvo condicionada a la comunidad y requería también de mejores condiciones de salud, a fin de sacar a los niños y las niñas de su inferioridad somática. El trabajo de investigación dio cuenta de la pésima construcción del inmueble -en la Colonia Obrera- y sus condiciones de iluminación, aspectos que afectaron la higiene de los escolares proletarios (Gómez, 1937).

Años más tarde -en 1943- en la obra Don Justo, describió su punto de vista sobre el maestro rural. Mostró su visión sobre la enseñanza, la formación de los discípulos y el papel del conocimiento escolar. El docente fue el elemento central en la formación moral-corporal de los estudiantes, su tarea fue evitar la degeneración, las deficiencias y el vicio (Viñao, 20Io). En este sentido, promovió la corporalidadciudadana y fue uno de los actores principales de la Unidad Nacional. El siguiente fragmento describe el papel del maestro como trabajador del Estado mexicano: 
Tengo que cumplir el amargo deber de comunicar a ustedes, con profunda pena, que nuestro querido don Justo ha dejado de existir. Dedicó toda su vida a la noble profesión de la enseñanza y murió, ejemplarmente, frente a su mesa de trabajo. El señor Ministro, que fue discípulo suyo, ha dispuesto que su cuerpo permanezca entre nosotros antes de que ocupe su lugar definitivo y le ha concedido el honor de ser cubierto con la Bandera Nacional para que comprendamos todos que el Gobierno de la República lo considera como un hijo predilecto de la Patria (Gómez, 1946, p. 416).

Este hijo predilecto de la patria murió trabajando y cubierto con la bandera nacional. De este modo, no sólo fue un trabajador al servicio del gobierno al que le rindieron honores; también fue un profesional con atributos especiales como mostrar el pensamiento humano, vivificar el espíritu de cada estudiante, reconocer lo uniforme que se requiere al formar; identificar lo diverso al trabajar con cada uno de los discípulos; formar dudas en el ejercicio de la capacidad humana de los jóvenes, y reconocer la soledad del saber (Gómez, I946). Enseñanza moral-corporal en la ciencia, en las explicaciones racionales y la duda constante.

Don Justo, personaje principal de la novela, reflejó el carácter y el estilo de la visión dominante del maestro rural de la época. Demostró al formador de mentes y cuerpos ante la comunidad escolar y los alumnos. Figura central del proyecto de Unidad Nacional. El sentido nacionalista encontró eco en la patria como sinónimo de madre y a la bandera como su insignia. La escuela educó, formó ciudadanos mediante los valores nacionalistas y colocó el cuerpo como muestra de estas cualidades individuales y sociales. El docente educó corporalmente al mexicano y la mexicana a través de la salud, la fuerza, el trabajo; la capacidad, la división sexual y los valores de la urbanidad, lo citadino y el progreso. Educación corporal que debe ser vista hoy a fin de comprender el sentido de nuestra ciudadanía mexicana escolar y sus implicaciones en lo individual y social. 


\section{Conclusiones}

El estudio de la corporalidad ciudadana mexicana; aplicada por Gómez Robleda, acentuó al individuo desde su condición física, moral, social y racial. El cuerpo objetivó los rasgos de la ciencia e interpretó su calidad ciudadana. Las condiciones morales en las que vivió el mexicano y la mexicana de mediados del siglo XX, y la circunstancias que lo rodearon, influyeron en la interpretación que se hizo de su vida personal. En lo social, la interpretación "racialista" y las capacidades productivas de la condición física; crearon los valores de productividad y la moral de control económico. La ciudadanía moderna, progresista y civilizada, dejó entrever la diferenciación de los sujetos fuera de la óptica de la antropometría, la psicometría, la dactiloscopía y la biotipología. La mirada médica tendió a la homogeneización cultural, sirviéndose de argumentos eugenésicos, en pro del mestizaje mexicano, en detrimento de la diversidad en deportistas, obreros, indígenas y la multiplicidad de niñas y niños del país. La formación de ciudadanos estuvo acorde con el ideal de la Unidad Nacional, que objetivó las individualidades mexicanas desde un modelo ciudadano basado en el tipo $u$ hombre medio. La corporalidad ciudadana del hombre medio estuvo pensada desde el Estado, como el sujeto alejado de vicios y encaminado hacia una moral de progreso científico y productividad industrial. Una visión que ponderó las capacidades en detrimentos de las potencialidades de hombres y mujeres. Por último, la escuela como espacio de formación ciudadana de la nación, fue pensada desde el Estado y desde un espacio institucional acotado por el proyecto de Unidad Nacional; sin atender a la porosidad de las identidades cambiantes de lo mexicano. Un ciudadano objetivado desde su constitución corporal, basado en la alimentación, la salud y las medidas corporales de la civilidad, la modernidad, el progreso, lo citadino, la heterosexualidad y la capacidad; construyendo una subjetividad disciplinada en el cuerpo y el alma de trabajadores, obreros e indígenas que hoy dan cuenta de nuevas formas de ser ciudadano en México. 


\section{Referencias}

Acevedo, R. y López, P. (coords.) (2012). Ciudadanos inesperados. Espacios de formación de la ciudadanía ayer y hoy. México: COLMEX / CINVESTAV.

Agostini, C. (2018). Historia de un escándalo. Campañas y resistencia contra la difteria y la escarlatina en la ciudad de México, 19261927. En Historia moderna y contemporánea (pp. 287-3II). México: UNAM.

Aréchiga C., E. (2007). Educación, propaganda o «dictadura sanitaria». Estrategias discursivas de higiene y salubridad públicas en el México posrevolucionario, 1917-1945. Estudios de historia moderna y contemporánea de México, (33), 57-88.

Canchola, A. (1957). Relaciones sociales y económicas de la ciudad y el campo en México. En Revista Mexicana de Sociología, XIX (I), I523.

Fernández, E. (1947). Río escondido. México: Producciones Raúl de Anda. Recuperado de:

https://cvc.cervantes.es/artes/cine/mexico_ilustrado/rio.htm

Foucault, M. (1980). El discurso del poder. México: Folios Ediciones.

Foucault, M. (2002). Historia de la sexualidad. I. La voluntad de saber. México: Siglo XXI.

Foucault, M. (2007). Introducción. El nacimiento de la biopolítica. México: FCE.

Gavaldón, R. (1952). El rebozo de Soledad. México: Cinematográfica Televoz.

Gómez Robleda, J. (1937). Características biológicas de los escolares proletarios. México: SEP.

Gómez Robleda, J. (1940). Deportistas. México: SEP.

Gómez Robleda, J. (1943). Pescadores y campesinos tarascos. México: SEP, I943.

Gómez Robleda, J. (1946). Don Justo. México: SEP.

Gómez Robleda, J. (1947). Biotipología. México: Talleres Gráficos de la Nación. 
Gómez Robleda, J. (1948). La imagen del mexicano. México: SEP.

Gómez Robleda, J. y D’Aloja, A. (1947). Biotipología. México: Talleres Gráficos de la Nación.

Gómez Robleda, J. (1949). Los zapotecos. Monografía histórica, etnográfica y económica. México: UNAM.

Gómez-Dante, O., y Frenk, J. (2019). Crónica de un siglo de salud pública en México: de la salubridad pública a la protección social de la salud. Salud pública de México, 6I(2), 203-2II.

Granjas, J. (20II). El lenguaje escolar de la desigualdad en el umbral de la «primera oleada de expansión» de la enseñanza obligatoria. México en la segunda mitad del siglo XX. Revista Mexicana de Investigación Educativa, I6(48), I7-42.

Gudiño-Cejudo (2008). Educación higiénica y consejos de salud para campesinos en El Sembrador y El Maestro Rural, 1929-I934. En C. Agostoni (coord.), Curar, sanar y educar Enfermedad y sociedad en México, siglos XIX y XX. (pp. 7I-98). México: Universidad Nacional Autónoma de México, Instituto de Investigaciones Históricas / Benemérita Universidad Autónoma de Puebla. Recuperado de: http://www.historicas.unam.mx/publicaciones/publicadigital/li bros/curar sanar/494.html

Gudiño-Cejudo, M.R., Magaña-Valladares, L., y Hernández Ávila, M. (20I3). La Escuela de Salud Pública de México: su fundación y primera época, I922-I945. Salud Pública de México, 55(I), 8I-9I.

Herrán, S. (1916). Nuestros dioses antiguos. Ciudad de México: Palacio de Bellas Artes. Recuperado de: http://museoblaisten.com/Obra/202I/Nuestros-dioses-antiguos

Jiménez, C.S. (1938). Asistencia pública y medicina social. Gaceta Médica de México, 69(5), 44I-449.

Lara Huerta, M. (20I0). La dictadura sanitaria o la estatización de los biológico. Letras jurídicas, (22), 6-9.

Magaña Valladares, L. y Gudiño Cejudo, M. R. (2012). Reseña histórica de la Escuela de Salud Pública de México. Noventa años formando salubristas e investigadores para mejora la salud de la población. México: INSP. 
Maíz, C. (2008). Revisión del mestizaje en la obra de Henríquez Ureña. Armonías selectivas, omisiones y humanismo en una teoría cultural. $\quad$ ALPHA, 27(I4), 9-28. Recuperado en: https://dialnet.unirioja.es/descarga/articulo/2788477.pdf

Mantilla, V. (2019). Saturnino Herrán y el problema de la identidad. Recuperado de: http://www.munal.mx/es/conocemas/post/saturnino-herran-y-el-problema-de-la-identidad.

Melchor Barrera, Z. (2018). Eugenesia y salud pública en México y Jalisco revolucionarios. Letras históricas, (I8), 93-II5.

Negrete, A. (2016). Del discurso a la práctica estatal. La labor del Departamento de Psicopedagogía y Médico Escolar (1925-194I) en la educación, higiene, y salubridad de la infancia posrevolucionaria mexicana [tesis de maestría]. Centro de Investigación y Docencia Económica, México.

Pacheco, J.E. (1992). Las batallas en el desierto. México: Era. Recuperado de: https://es.slideshare.net/RigobertoRamirezi/pacheco-joseemilio-las-batallas-en-el-desierto-I2604840

Padilla, A. (2009). De excluidos e integrados: saberes e ideas en torno a la infancia anormal y la educación especial en México, I9201940. FRENIA, (9), 97-I34.

Piccato, P. (2012). Epílogo. De la ciudadanía a los ciudadanos: notas sobre la contin- gencia en la historia política. En A. Acevedo y P. López (coord.). Ciudadanos inesperados: espacios de formación de la ciudadanía ayer $y$ hoy (pp. 315-336). México: COLMEX/CINVESTAV.

Ramírez Vega, N. (20I4). El rebozo de Soledad. El laberinto cultural. Recuperado de: https://laberintocultural.wordpress.com/20I4/I2/25/el-rebozode-soledad/.

Reggiani, A.H. (2019). La eugenesia en América Latina. México: El Colegio de México.

Rodríguez de Romo, A.C., y Rodríguez, M.E. (1998). Historia de la salud publica en México: siglos XIX y XX. História, Ciências, Saúde Manguinhos, 5(2), 293-3IO.

Saade Granados, M. (2004). ¿Quiénes deben procrear? Los médicos eugenistas bajo el signo social. Cuicuilco, II(3I), I-36. 
Stern, A. (200o). Mestizofilia, biotipología y eugenesia en México posrevolucionario: hacia una historia de la ciencia y el estado, 1920-1960. Relaciones. Estudios de historia y sociedad, (8I), 59-9I.

Stern, A. (2002). Madres conscientes y niños normales: la eugenesia y el nacionalismo en México posrevolucionario, 1920-1940. En L. Cházaro (ed.), Medicina, ciencia y sociedad en México, siglo XIX (pp. 293-336). Zamora: El Colegio de Michoacán / Universidad Michoacana de San Nicolás de Hidalgo.

Suárez y López Guazo, L. (I999). La influencia de la sociedad eugénica mexicana en la educación y en la medicina social. Asclepio, (52), 5I-84.

Suárez y López Guazo, L. (2005). Eugenesia y racismo en México. México: UNAM.

Suárez y López Guazo, L., y Ruiz Gutiérrez, R. (200I). Eugenesia y medicina social en el México posrevolucionario. Ciencias, (6o-6I), 8o-86.

Urías Horcasitas, B. (2007). Historias secretas del racismo en México (I9201950). México: Tusquets.

Vargas Domínguez, J. (2015). Conexiones internacionales en fisiología, eugenesia y nutrición: las investigaciones sobre el metabolismo Otomí en el México posrevolucionario. Ludus Vitalis, 23(43), 83IO4.

Vigarello, G. (1997). Histoires des corps: entretien avec Michel de Certeau, Esprit, 1982, 2, p. I79-90 [Traducción: Alejandro Pescador]. Historia y Grafía. Recuperado de: http://mastor.cl/blog/wp-content/uploads/2015/o8/DE-CERTEAU-MHistoria-de-cuerpos-entrevista.pdf

Viñao, A. (20I0). Higiene, salud y educación en su perspectiva histórica. Educar, Curitiba, (36), I8I-2I3.

\section{Notas:}

${ }^{\text {I }}$ Estas corrientes, apoyadas en Mendel, Darwin y Galton, implicaron una visión "científica" del ser humano y lo responsabilizaron -desde el nacimientode sus futuras capacidades, aptitudes y habilidades. Mendel estableció la herencia como responsable del futuro individual. Darwin indicó la selección 
natural como parte importante del avance social. Galton señaló la determinación de la inteligencia de manera innata y la forma en que esta definía la vida futura de un adulto.

${ }^{2}$ La eugenesia ("El buen nacimiento"), buscó establecer criterios científicos para el mejoramiento y depuración racial de la población. Esta ciencia elaboró criterios de medición social, intelectual, económica y política de las personas a fin de establecer la calidad de hombres y mujeres.

${ }^{3}$ El hombre medio fue un concepto que buscó, a partir de la medición del cuerpo del mexicano (hombre o mujer), su caracterización física. Se pretendía evaluar su condición biológica, usando estrategias políticas, culturales y educativas en su desarrollo.

${ }^{4}$ La modificación en las políticas de urbanización llevó a la reducción de la población rural de $75 \%$ a principios de siglo al 57,4 \% (I4 millones 807 mil 534 habitantes) a mediados del siglo XX. Aumentó la población urbana de $25 \%$ a 42,6\% (Io millones 983 mil 438 habitantes) (Canchola, I957). Lo anterior, conformó un cambio demográfico en la población mexicana a favor de la vida urbana y sus valores.

Este artículo se publica bajo una licencia de Creative Commons Reconocimiento-NoComercial 4.0 Internacional, y puede ser usados gratuitamente para fines no comerciales, dando los créditos a los autores y a la revista.

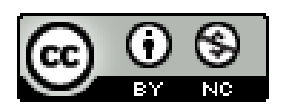

